\title{
Editorial
}

\section{Docencia universitaria en tiempos de pandemia}

\author{
Lourdes Lledó García ${ }^{1}$ \\ Decana Facultad de Medicina y Ciencias de la Salud de la Universidad de Alcalá; lourdes.lledo@uah.es; \\ https://orcid.org/0000-0001-5387-6792
}

DOI: https://doi.org/10.37536/RIECS.2020.5.2.236

El año 2020 lo recordaremos como una pesadilla, un desastre humanitario, sanitario, social, con un terrible impacto en todos los aspectos cotidianos de la vida de la población mundial. Desde la primera notificación de un caso de neumonía producida por un virus hasta entonces desconocido, a finales de diciembre de 2019, los cambios que se han producido en nuestras vidas han sido vertiginosos. Sin duda, la pandemia por este nuevo virus, SARS-CoV-2, va a dar lugar a que, cuando el periodo crítico pase, se planteen debates que conducirán a cambios, que previsiblemente nos harán mejorar.

Esta pandemia está siendo un reto en muchos ámbitos, y por supuesto en la docencia universitaria. En nuestro país a partir de mediados de marzo se interrumpió la actividad docente universitaria presencial de forma abrupta lo que supuso un reajuste metodológico sin precedente en nuestra historia tanto para docentes como para estudiantes. Sin embargo, la reacción ha sido buena, pese a las deficiencias lógicas observadas, pero lo cierto es que se ha realizado un gran esfuerzo y se ha revelado una capacidad de comprensión y adaptación a las circunstancias digna de mención.

Después del trauma inicial la comunidad universitaria. como el resto de la sociedad, comprendió que esta situación extraordinaria y global se iba a prolongar y que había que adaptarse y recurrir a formatos y metodologías mixtas que permitieran continuar con la formación en entornos lo más seguros posibles. Así, se ha recurrido de forma generalizada a un modelo mixto, presencial y virtual, desarrollando en tiempo récord el manejo de plataformas virtuales educativas que han requerido un proceso de formación de estos recursos digitales, por parte de gestores, docentes y estudiantes y para el que se han invertido, no solo recursos económicos sino humanos tanto en la organización como en la búsqueda y diseño de alternativas y/o herramientas de calidad. La colaboración entre diferentes instituciones está siendo muy relevante y ciertamente constituye uno de los efectos positivos de esta situación.

Este modelo mixto, conlleva muchos retos, entre ellos valorar qué partes del programa se pueden implementar virtualmente y cuáles deben ser obligatoriamente presenciales, aumentar la innovación en el diseño de metodologías/herramientas docentes con el fin de conseguir la consecución de objetivos de aprendizaje, mucho más asequibles de alcanzar con actividades presenciales, mantener la socialización y comunicación fundamentales para el aprendizaje en valores y mantener la equidad en recursos y oportunidades, entre otros.

Evidentemente, además de los retos y dificultades el modelo mixto también ofrece ventajas ya que facilita la comunicación con instituciones y grupos de cualquier ámbito y lugar: se están desarrollando muchas actividades docentes entre diferentes universidades de cualquier lugar del mundo, en forma de conferencias, mesas redondas, sesiones de trabajo...etc. Todas estas actividades mejoran el desarrollo de competencias transversales (comunicación, trabajo en equipos multidisciplinares, entre otras).

Así, ante cualquier crisis además de intentar superarla, deberíamos valorar las oportunidades de mejora que se nos ofrecen. En este caso la comunidad universitaria está intentándolo, el futuro nos dirá si lo conseguirá. 
(C) 2020 por los autores; Esta obra está sujeta a la licencia de Reconocimiento 4.0 Internacional de Creative Commons. Para ver una copia de esta licencia, visite http://creativecommons.org/licenses/by-nc-nd/4.0/. 